\title{
Fronteras FIJAS, VALOR DE CAMBIO Y CULTIVOS ILÍCITOS en el Pacífico caucano de Colombia
}

\author{
Stella Rodríguez \\ ESTUDIANTE DE DOCTORADO EN GEOGRAFÍA \\ UniversidAd FEDERAL de Río dE JANEIRO \\ lunsella@gmail.com
}

\begin{abstract}
Resumen
[STE ARTí́CULO SE CENTRA EN LOS CAMBIOS EN LAS RELACIONES ENTRE LOS INDÍGENAS EPERARAEsiapidara y las comunidades negras del río Saija en el área rural del municipio de Timbiquí (departamento del Cauca, Colombia), a partir de la acentuación de las diferencias étnicas en el proceso de titulación colectiva. Se arguye que la titulación llevó a algunos desencuentros y al endurecimiento de las fronteras étnicas pero no constituyó por sí misma un conflicto, por lo cual se analizan otros factores asociados con el arribo de los cultivos ilícitos.

Palabras Clave: relaciones interétnicas, titulación colectiva, Pacífico colombiano, conflictos territoriales.
\end{abstract}

\section{FiXed Frontiers, EXCHANGE VALUE AND ILLICIT CROPS in the Colombian Pacific coast}

\begin{abstract}
THE ARTICLE FOCUSES ON THE CHANGES IN THE RELATIONSHIP BETWEEN INDIGENOUS EPERARA-SIAPIdara and Afrocolombian communities from the Saija River in the rural Timbiqui municipality (Cauca, Colombia), due to the accentuation of ethnic differences in the process of collective land titling process. It argues that the titling process brought some contradictions and a "hardening" of ethnic frontiers but did not in itself constitute a motive of conflict. As a result, other factors associated with the arrival of illicit crops are analyzed.

KEY WORDS: Interethnic relations, collective land titling, Colombian Pacific coast, territorial conflicts.
\end{abstract}

\section{Revista Colombiana de Antropología}

Volumen 44 (I), enero-junio 2008, pp. 4I-70 


\section{INTRODUCCIÓN}

$\left[\begin{array}{l}\text { in } \\ \mathrm{y}\end{array}\right.$ STE ARTÍCULO EXAMINA ALGUNAS TRANSFORMACIONES EN LAS RELACIONES interétnicas territoriales entre los indígenas eperara-siapidara y las comunidades negras que comparten un territorio en la cuenca baja del río Saija -área rural del municipio de Timbiquí en el departamento del Cauca, al sur occidente de Colombia (véase el mapa, p. 44)-. El análisis se basa en el proceso de titulación territorial colectiva ${ }^{1}$ que incluyó ambos grupos y en los conflictos interétnicos que surgieron después de la legalización

I. La titulación territorial colectiva consiste en el reconocimiento del derecho concedido a los grupos étnicos de la propiedad de la tierra. En Colombia este proceso ha tomado forma a partir de leyes que respaldan las demandas territoriales de esos grupos. Los resguardos para grupos indígenas están amparados en una legislación conquistada durante décadas de lucha y en la ley I60 de I994. En el caso de las comunidades negras, la propiedad definitiva de sus tierras se definió en la ley 70 de 1993. En ambos casos, la Constitución políitica de I99I concreta las bases y el respaldo jurídico de estas legislaciones especiales. de la posesión territorial y la llegada de los cultivos de coca. Aun cuando el caso se refiere a las organizaciones étnico-territoriales de la parte baja del Saija, algunos de los elementos analizados se pueden extender a otras comunidades a lo largo del río e, incluso, a otras áreas de la región Pacífica.

Para responder a la insistencia de Barth (I969) en develar cómo surgen las distinciones étnicas en un área determinada, el texto busca ver cómo se modelaron a partir de la titulación colectiva en la zona Pacífica, concentrándose en la dimensión territorial de las relaciones interétnicas a la luz de procesos externos como el aumento de las tierras destinadas a los cultivos de uso ilícito y la colonización creciente, que desde la década de 1980 han venido imbricándose más y más en la vida cotidiana de esos grupos étnicos. Asumo la etnicidad como un aspecto de las relaciones sociales y no como una propiedad cultural de las etnias. De acuerdo con la propuesta de Barth, esta no es un fenómeno aislado ni existe fuera de la relación con otros grupos o el estado; en esa perspectiva, la identidad étnica es aprendida, activada políticamente y no se encuentra necesariamente anclada en el pasado.

En su dimensión territorial, el conflicto armado que vive Colombia es, sin duda, uno de los marcos para entender la configuración actual de las relaciones interétnicas en la región del Pacífico. Sin embargo, está fuera del alcance de este documento profundizar en sus efectos en los territorios étnicos o sobre la 
manera como lo han asumido las organizaciones étnico-territoriales. Aquí sólo podemos ratificar que la principal causa de los conflictos étnicos en el mundo continúa asociada a la defensa de los derechos territoriales (Nietschamnn, I987; Eriksen, I993). En la medida en que la producción y el tráfico de drogas son motivos de disputa en el Pacífico, deben ser considerados como otros factores que median las relaciones entre el estado colombiano y los grupos étnicos, al igual que las formas usadas por este para contrarrestarlo; por ende, cultivos, tráfico y medidas de control moldean también las demandas de las comunidades por la defensa del territorio.

Me interesa explorar una situación en la que si bien la titulación llevó a algunos desencuentros y al endurecimiento de las fronteras étnicas, producto en parte de las asimetrías entre los derechos legales reconocidos a cada grupo ${ }^{2}$, por sí misma no

2. Para un análisis más detallado sobre las asimetrías en los derechos adquiridos por ambas etnias, véase Arocha, I996. desembocó, en el caso de Timbiquí, en un conflicto violento, como han afirmado Villa (I998) y Offen (2003). En este escrito discutiré también otros factores que influyen en las relaciones y los conflictos sociales y territoriales en el Pacífico, como el problema de las drogas de uso ilícito y la búsqueda de tierras para la siembra de coca para su producción.

\section{TERRITORIALIDAD A DÚO:}

APROPIACIÓN, USO, MANEJO Y CAMBIO

L RÍO SAIJA, QUE TRIBUTA SUS AgUAS Al OCÉANO PACíFICO, ES CONOCIDO For abrigar a lo largo de sus llanuras selváticas descendientes Lde esclavos africanos y, en menor proporción, indígenas eperara-siapidara, pertenecientes a la familia de los embera. Desde la llegada de los primeros negros, ambos grupos han convivido y realizado intercambios materiales, espirituales simbólicos y comerciales, en una relación que ha incluido el flujo de información y de bienes y la interacción entre las dos etnias.

Etnografías sobre otros lugares del Pacífico han destacado la convivencia pacífica que por mucho tiempo definió las relaciones entre ambos pueblos, convivencia descrita como un espacio 


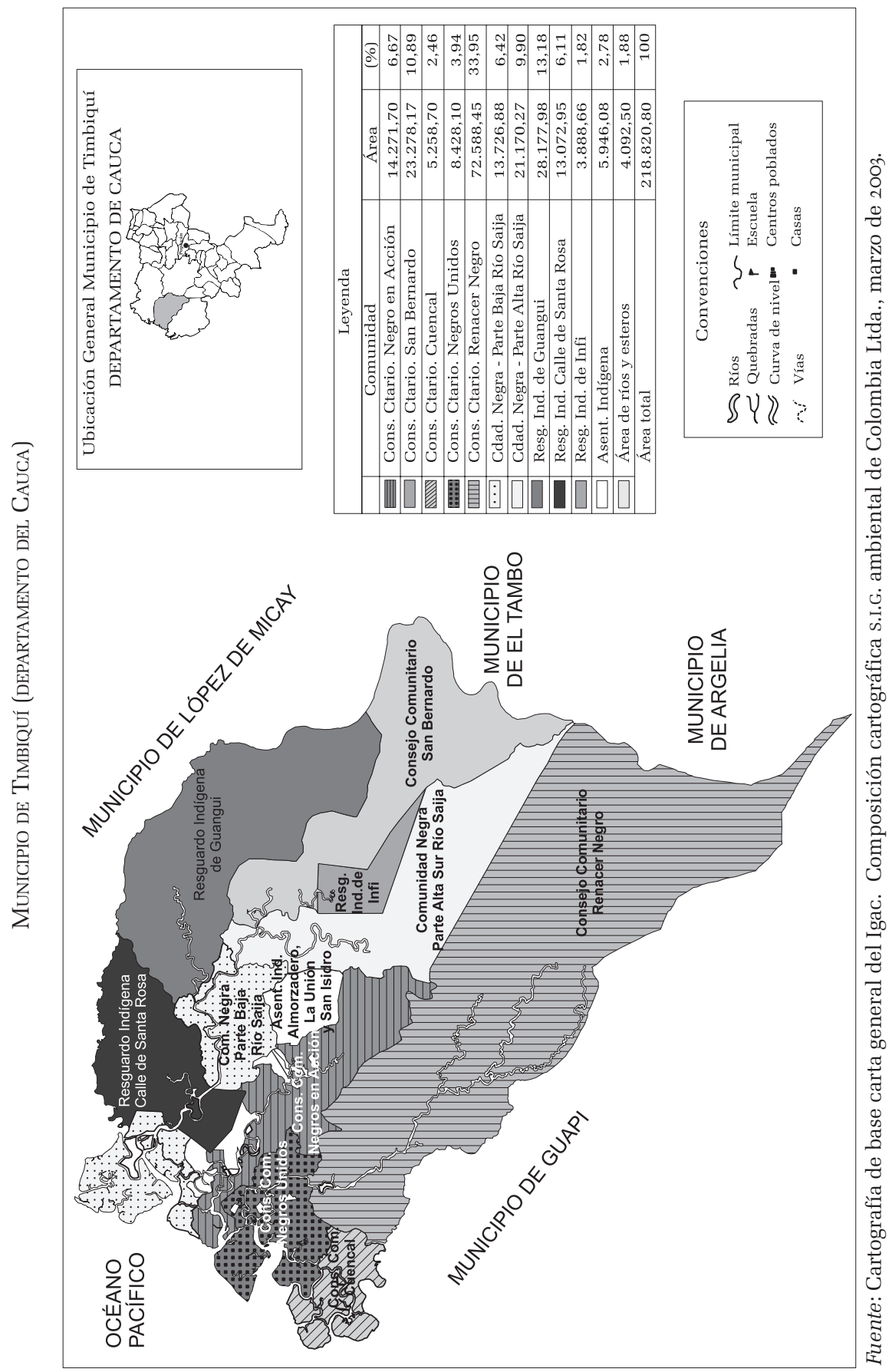


de intercambios rituales, mágicos y sanatorios, mediados por relaciones de compadrazgo y parentescos espirituales (véanse Arocha, I996, I998, I999; Losonczy, I997). Como anota Eriksen (I993), las fronteras étnicas no siempre corresponden a fronteras territoriales. En este caso, las experiencias entretejidas produjeron un espacio definido por una territorialidad compartida, en la que cada grupo inscribió sus códigos en las selvas, los esteros, los ríos y demás lugares diferenciados para el poblamiento, la recolección, la pesca, la tala y la siembra.

Si se asume la territorialidad de acuerdo con los preceptos de Sack (I986), es decir, como una estrategia de influencia y control sobre los recursos y los habitantes de un espacio, la manera como la gente se organiza allí y el significado que le atribuye a cada lugar, podemos concluir que la organización del espacio en el río Saija se estableció por medio de pactos y acuerdos tácitos que regulaban el uso y el aprovechamiento de los recursos. Estas prácticas, propias del derecho consuetudinario, propiciaron una territorialidad en la que no existían límites fijos o fronteras estáticas. En ausencia de una línea geográfica, el espacio estuvo dado por la continuidad de las semejanzas y el desvanecimiento de las diferencias, idea que ilustra el siguiente aparte de mi diario de campo:

Los sábados, Tomasa, una negra grande y curtida por los años, se despierta más temprano que de costumbre, raja leña, enciende su horno y empieza a amasar la harina de trigo que llega los jueves en barco desde Buenaventura. El aroma del pan caliente de Tomasa se levanta con el día, con la gente de Puerto Saija, que inicia la jornada y espera a los vendedores de pescado y carne de monte, pipa y, según la época, chontaduro o naidí.

Los fines de semana los días son bulliciosos, los niños no van a la escuela y las calles de lodo recubiertas por puentecitos de madera están llenas de sus gritos y juegos y de la música estruendosa de parlantes gigantes. De acuerdo con el flujo de las aguas del río, afectado por la marea, Tomasa sale en su potrillo ${ }^{3}$ a vender el pan. Sólo unos pocos alcanzan a comprarle, porque ella va directo al caserío de los cholos $^{4}$ a venderlo todo allá. Con la marea vaciando Tomasa regresa a Puerto Saija; no trae dinero pero su potrillo viene lleno de cañas de azúcar, cañas de su cañaveral que el compadre cholo le hizo el favor de rozar. Al verla llegar sus vecinos le preguntan, en tono burlón: -Tomasa, y ahí,

3. Embarcación pequeña para una sola persona.

4. Etnónimo local que los negros usan para designar en general a los indígenas. 
¿cómo te fue con tus maridos cholos? A lo que ella responde, radiante -Buenos están, mejor que maridos, isólo amores!

Tomasa descansa el domingo, aguardando el lunes para ir al trapiche y moler la caña. Con ese guarapo ella prepara el biche ${ }^{5}$, bebida alcohólica que aprendió a destilar con los cholos. Todo el biche lo envía

a Buenaventura y la ganancia le

5. Aguardiente de caña de azúcar destilado artesanalmente.

6. Nombre dado a las bebidas que se preparan con fines curativos. Las botellas curadas son elaboradas por los curanderos a partir de la mixtura de biche con hierbas medicinales. sirve para comprar harina, pagar en el trapiche y darle parte a su compadre cholo, que además de ayudarla a mantener limpia la finca busca plantas medicinales para las botellas curadas $^{6}$ que ella manda a preparar a un cuñado de

su compadre. No siempre se vende el biche, no siempre llega harina del puerto, pero si falta el pan el cholo le manda a Tomasa racimos de plátano, ñames y yucas o le vende fiada la carne de monte, aunque ella esté sin dinero (notas, mayo de 2004).

Como se aprecia en el aparte anterior, en el bajo río Saija el espacio se organizó con base en las cosmogonías locales y las redes de relaciones sociales que configuraron unas reglas y derechos de acceso a recursos y tierras, reglas que se sustentaban en acuerdos tácitos no siempre estandarizados y en la solidaridad y la convivencia que se urdió a lo largo de los años. En la región las características geofísicas guiaron un poblamiento inicial marcado por la dispersión de los asentamientos, hoy en día cada vez más nucleados por las pretensiones de las antiguas misiones catequizadoras y las exigencias comerciales que han ido conduciendo a la urbanización de los entornos (Aprile-Gniset, I993). Antes de la titulación, los espacios colectivos y las parcelas de cultivos familiares estaban diseminadas, sin que se pudiera establecer un bloque totalmente distinguible u homogéneo para una u otra etnia. En términos generales no había unidades reconocibles, sino, más bien, un continuo en el cual la separación de territorios entre grupos y aún entre unidades familiares colindantes era subjetiva y variable. En medio de esa continuidad social a continuación se destacarán, a grandes rasgos, algunas singularidades del ejercicio de territorialidad de cada etnia. 


\section{TERRITORIALIDAD AFRODESCENDIENTE}

$\int^{\mathrm{E}}$ ESDE EL SIGLO DIECIOCHO LOS DESCENDIENTES DE ESCLAVOS EMPRENDIERON un camino de auto reconstrucción social, desde los centros mineros a las tierras bajas del Pacífico. En su viaje reconocieron la geografía de diversos paisajes, poblaron playas y tierras firmes, cultivaron montes, navegaron ríos y esteros y dominaron el mar (Almario, 1996). Al tiempo, imprimieron en cada lugar su huella, llenaron de historias los espacios, los colmaron con sus seres imaginarios y hallaron la morada espiritual para sus ancestros.

Las sociedades negras del Pacífico han accedido a la tierra a partir de su trabajo, es decir que se han apropiado de ella laborando nuevas parcelas a medida que las requieren. Abrir una parcela significa desmontar la selva de los lugares aptos para cultivar. Un lote nuevo puede estar lejos de las otras parcelas familiares, con lo cual una familia puede poseer varias en diferentes lugares sobre el mismo río. Las inundaciones periódicas de largas fajas de tierras y la costumbre de rotarlas para el barbecho y el descanso hacen que en esas selvas las tierras aptas para cultivar sean pequeñas en extensión y estén distantes.

La posesión es el derecho que tienen los integrantes de una familia a utilizar uno o varios lotes de tierra, ubicados por lo general frente a un río o una quebrada, que constituye siempre un lindero. El terreno tiene otros linderos, a partir de los cuales empieza el dominio de otra familia, pero suelen ser difusos y en ocasiones están marcados por mojones como rocas o árboles. Hacia el fondo están los espacios comunitarios, los denominados centros, confines, baldíos o respaldos, donde se practican la caza y la recolección. Tradicionalmente, la propiedad de la tierra descansó sobre la estructura familiar y comunitaria, y este nexo de parentesco limitó el acceso de personas no vinculadas por los lazos familiares.

La intrincada red entre los troncos familiares ${ }^{7}$ (Arocha, I999; Friedemann, I993) conduce, así 7. Sistema de organización del parentesco entre las familias negras del Pacífico que identifica un ancestro fundador y sigue un modelo poligínico y exogámico de parentela extendida. Su origen se remonta posiblemente al sistema de cuadrillas, forma social de explotación minera durante la colonia. La matrilinealidad característica del sistema se origina en la cuadrilla minera, en la que la mujer desempeñó, en el ámbito doméstico, un papel articulador de las relaciones de parentesco (véase Romero, I99I).

mismo, a que habitantes de una vereda posean por herencia tierras agrícolas y forestales en otras, incluso en otros ríos, y, con la nueva legislación, en territorios de 
otros consejos comunitarios. Quien pertenece a un tronco tiene derechos de residencia, trabajo y herencia sobre las tierras mineras y las chagras de cultivo reclamadas por el antepasado como propiedad de su descendencia. Además, existen derechos activos y latentes, lo cual quiere decir que una persona utiliza sus opciones de filiación materna o paterna, manteniendo activa una de ellas.

A la tierra se accede también por herencia: en el río Saija cuando los hijos de nacimiento o de crianza -hombres y mujeres- se independizan y forman nuevos hogares reciben de sus padres tierras donde trabajar; conocidas como plante, esas tierras se transmiten por doble vía: paterna y materna. El matrimonio con una pareja de otra localidad da derecho también a participar del usufructo de los terrenos del cónyuge, que desaparece cuando se disuelve la unión; sin embargo, este derecho prevalece para los hijos de dicha unión. La transmisión del patrimonio se mantiene cuando los parientes migran hacia Buenaventura, Cali o Popayán, y se activa a su retorno o al regreso de hijos o nietos. Mientras un núcleo familiar está ausente otros parientes de la red usan y aprovechan las tierras, lo que garantiza que los caminos de acceso se mantengan limpios y las zonas de cultivo desmontadas.

Otra manera de conseguir tierras es mediante la compra: la venta de usufructos y mejoras ${ }^{8}$ entre miembros de la misma comunidad es una práctica común que hasta hace un tiempo estuvo regulada por normas consuetudinarias, las cuales nunca estuvieron respaldadas por títulos de propiedad. Esas transacciones dependían, primero, del grado de parentesco de los vendedores y de la aprobación de los colindantes. La gente solía vender cocales -cultivos de palma de coco- o cañaverales maduros por la imposibilidad de cosecharlos o para superar alguna emergencia en salud o educación de los hijos, y quien compraba lo hacía como gesto de solidaridad.

8. Se entiende por mejoras los trabajos que hacen apto un terreno para ser cultivado y lo valorizan: desmonte, limpieza, apertura de caminos, etcétera.

9. El Incoder (Instituto Colombiano de Desarrollo Rural), antes Incora (Instituto Colombiano de la Reforma Agraria), es el órgano ejecutor de la política agropecuaria del estado colombiano; considera como mejoras: "cunetas", o zanjas de cerca de I metro de ancho utilizadas para transportar las trozas de madera o tucos desde el bosque hasta las quebradas y ríos, aprovechando el alto nivel freático de estos humedales turbosos. Estos elementos determinan la propiedad en los bosques.
El arrendamiento ha sido otro mecanismo para trabajar la tierra, y por lo general ha sido usado para cultivos transitorios; el pago depende de las características del terreno y de las mejoras que tenga, tales como zanjas o cunetas ${ }^{9}$, drenado, desmonte y existencia de cultivos permanentes o especies maderables. 
Volumen 44 (I), enero-junio 2008

\section{TERRITORIALIDAD INDÍGENA}

L RESGUARDO ES LA FORMA DE PROPIEDAD COLECTIVA DE LOS INDÍGENAS Y

ha sido una de sus principales banderas de lucha como pue-

-blo. Aun cuando se sustenta en formas tradicionales de uso y tenencia y su historia se puede rastrear desde la colonia, en Colombia sólo desde I980 empieza a consolidarse una política de estado que reconoce los derechos de propiedad territorial de los pueblos indígenas, al otorgarle carácter legal a los resguardos. Esa política se reafirmó en la Constitución política de I99I (Sánchez, Arango et al., 2002). El acceso a la tierra en los resguardos está dado por el trabajo en ella y por la tradición del derecho consuetudinario o de origen; en él se reconoce la posesión individual y familiar sobre las parcelas cultivadas, así como el usufructo de las heredadas.

En el caso de la parte baja del río Saija las familias indígenas no trabajan tierras en común con otras familias y procuran que dentro del sector territorial de la parcela no se instalen personas sin vínculo de parentesco. Las comunidades indígenas locales tienen gran movilidad territorial, como estrategia de adaptación a la selva tropical y reacción defensiva a la conquista y colonización de su territorio. En esta dinámica se presenta el abandono temporal de algunas zonas, sin que ello signifique que dejan de ser parte integral del mismo ${ }^{10}$.

IO. El uso, el manejo y la apropiación territorial de los indígenas se debe analizar teniendo en cuenta su cosmovisión. Los eperara-siapidara conciben tres mundos: el mundo de arriba, en donde se encuentra el sol, Tachi Akoré; el del medio, Tachi Ehua, nuestra tierra, en donde viven los eperara. Este mundo inicia en To Khi-cabecera de los ríos- y termina en To Kharra -bocanas-; el tercer mundo es el de abajo o Anta Aramoora EOKA -espacio de los tápanos-. El sol circula en los tres mundos y les da la luz. La Tachi Nawe, guía espiritual de los eperara-siapidara y cuyo cargo es heredado de madre a hija, es la mediadora entre los tres mundos. Esta concepción señala la relación que tienen los eperara con las bocanas y con el mar, adonde se desplazan en distintas épocas del año para recoger conchas y mariscos. Muchas familias tienen parcelas en las bocanas y en las playas, lo que genera una relación permanente con los pobladores negros de estas zonas bajas. Esta relación se manifiesta en compadrazgo, intercambio comercial y en algunas tensiones.

\section{REgLAS DEL ESPACIO COMPARTIDO}

A TENENCIA DE LAS PARCELAS Y EL SISTEMA TRADICIONAL DE HERENCIA HAN sido interferidas por operaciones de compraventa y arrenda-miento entre indígenas y entre estos y afrodescendientes. Lo 
habitual era que esas transacciones estuvieran basadas en relaciones sociales de colaboración, solidaridad y reciprocidad, así como de intercambio espiritual, como el compadrazgo. En ambos casos ese tipo de arreglos estuvo sustentado en el valor de uso de la tierra y no en un valor de cambio. Un afrodescendiente, por ejemplo, podía dar a su compadre indígena algunas tierras para cultivar, a cambio de algún beneficio espiritual o curativo.

Desde el punto de vista mágico-simbólico ambos grupos consideran peligrosos los matrimonios interétnicos. Por lo general, los poquísimos casos que se presentan son entre una indígena y un negro. En los dos que registré en mi trabajo de campo las mujeres debieron irse a vivir a la comunidad negra y perdieron sus derechos territoriales en el resguardo. Se me explicó que si sus hijos quieren regresar a reclamar derechos por vía de los abuelos maternos pueden hacerlo, aun cuando este caso no se ha presentado.

En cada etnia el acceso a los recursos ha estado mediado por reglas y pactos consuetudinarios que reposan en las relaciones sociales. Hasta hace poco los acuerdos implícitos fueron la norma determinante para regular la adquisición de tierras. Había desacuerdos, como se relató en algunas entrevistas hechas a personas de cada grupo, pero sin fracturas considerables en las relaciones, gracias a la mediación de personas más viejas o a la intervención de quienes habían llegado primero a determinado lugar y daban cuenta de pactos anteriores.

Para ambos grupos los espacios de uso colectivo son aquellos donde se practica la caza y se recogen frutos silvestres, plantas medicinales, maderas y bejucos para la construcción; el mismo carácter colectivo recae sobre el uso de ríos, quebradas y esteros. La utilización de las zanjas y los drenajes para sacar trozas de madera con destino comercial requiere el permiso del dueño, la ayuda en su mantenimiento o el pago de algún valor establecido previamente.

El acceso a los recursos en los territorios de uso colectivo no ha sido ajeno a la confrontación causada por la extracción de recursos naturales con valor monetario, como la madera, cuyo comercio fue creando divisiones. La explotación de productos forestales se consolidó en el Pacífico caucano desde mediados de la década de I970 por la madera que demandaba el proceso de urbanización del país, el advenimiento de una navegación más rápida y el uso de navíos con mayor capacidad. Familias negras como los Montaño del alto Saija y Santa Rosa migraron a Buenaventura 
en los años I950 y fueron las primeras en establecer contacto con aserríos del puerto que compraban los cortes de madera de sus zonas. Poco a poco, y por lazos de parentesco, el comercio maderero se fue extendiendo a lo largo del río.

En el caso de los indígenas las migraciones fueron posteriores, y esto influyó en que el establecimiento de relaciones comerciales con el puerto de Buenaventura fuera menos intenso y que muchas veces estuviese mediado por familias negras. De ahí que la explotación maderera por parte de los indígenas diferiese en tiempo e intensidad de la que iniciaron las familias negras.

Más tarde, a finales de la década de I970, la concesión de licencias de explotación zonificada de madera por parte de la Corporación Autónoma Regional del Cauca (Corpocauca, entidad oficial de regulación ambiental) fue decisiva para delimitar las áreas de explotación de los bosques, porque antes de la ley 70 de I993 esta actividad era permitida en las llamadas zonas baldías, que excluían las tierras indígenas. Estas diferencias crearon algunas divisiones entre ambas etnias.

Las demandas por la madera y por la expedición de licencias sentaron, de alguna forma, un precedente en el establecimiento de límites territoriales entre ambas etnias. La legislación especial indígena y las asimetrías que en términos de derechos se dieron para cada grupo en la Constitución de i99I contribuyeron de manera significativa a acentuar las diferencias (Arocha, I996).

Por último, los sistemas de alianzas interétnicas cambiaron radicalmente con el advenimiento de la siembra de coca y la disputa territorial entre actores armados interesados en su control. En consecuencia, es inadecuado afirmar que el endurecimiento de la frontera étnica y la erosión de los mecanismos de convivencia fueron detonados sólo por la legalización territorial.

\section{Aspectos legales}

DE LA TERRITORIALIDAD EN EL PACífico

AS CARACTERÍstiCAS POBLACIONALES DEL RÍO SAIJA RESPONDEN A LAS generalidades del Pacífico colombiano, que se desarrolló como Luna región marginal, relativamente aislada por la falta de vías de comunicación con el interior del país, pero depositaria de 
inmensas riquezas naturales inventariadas y saqueadas desde la colonia en sucesivos ciclos de extracción de productos biológicos y minerales incentivados por capitales foráneos que vieron en la región un gran reservorio de recursos (Restrepo y Leal, 2003).

La región pacífica fue definida por el estado como una zona baldía, es decir se reconocía como área sin propietarios. A partir de la ley 2a de 1959 el pacífico recibió el carácter de "zonas forestales protectoras" y "bosques de interés general". La ley representó a la región como un espacio vacío, desconociendo a sus habitantes -negros e indígenas-, y negó sus derechos de propiedad territorial. Designó un carácter de reservorio para los bosques nacionales, donde el estado se otorgaba el derecho de adjudicar áreas de explotación maderera a partir de licencias expedidas por el Ministerio de Agricultura. Los baldíos sólo se adjudicaban como parte de planes de explotación extractiva, dando continuidad a las formas históricas de apropiación de recursos por parte de intereses privados y, por lo general, externos a la región. El estado tenía derecho también de hacer sustracciones a las áreas de la reserva forestal en aquellos lugares de interés para la colonización libre o dirigida, la constitución de reservas indígenas, la conservación ambiental, la investigación científica y la defensa nacional, entre otros. Para Villa (1998) la sustracción a la reserva fue el mecanismo por el cual se cambiaron la destinación y el uso de los terrenos baldíos y se fueron escribiendo sucesivos capítulos de afectación legal sobre el mapa contemporáneo del Pacífico.

Como parte de este esquema, los habitantes del río Saija, al igual que otros de la región, estuvieron por años sin legalizar la situación de tenencia de sus tierras; no obstante, las usufructuaron con relativa autonomía, al tiempo que estuvieron vinculados al mercado de manera marginal e intermitente en los ciclos de extracción de oro en el río Timbiquí y de productos forestales en el Saija. En 1965 tuvo lugar la primera sustracción de la reserva forestal del Pacífico para el área correspondiente al departamento del Cauca: mediante el proyecto Cauca ${ }^{\circ}$ I (resolución 45 de I965) el Instituto Colombiano de la Reforma Agraria impulsó un programa de colonización dirigida que apoyaba la siembra de coco y la adjudicación individual de fincas. El impacto de esa medida estuvo lejos de ser masivo, y con ella apenas se beneficiaron treinta y seis familias negras con títulos individuales que cubrían alrededor de trescientas hectáreas en el río Saija, títulos 
que nunca fueron inscritos en la Oficina de registro de instrumentos públicos, con lo que cualquier acción legal de compraventa se dificulta.

En términos generales, a partir de los cambios suscitados por la Constitución política de I99I la afectación legal de estos territorios dio un vuelco total en favor del reconocimiento de la propiedad colectiva a las comunidades negras ${ }^{11}$ (Agudelo, 2004), pues como se ha dicho, los resguardos venían consolidándose desde antes. De acuerdo con Arocha (I998) existía la esperanza de que a pesar de las asimetrías en la legislación étnica la consoli-

II. Este giro se concretó en el artículo transitorio 55, que desembocó luego en la ley 70 de 1993 o ley de comunidades negras, y la reglamentación del capítulo III a partir del decreto 1745 de I995. dación de esas leyes especiales contrarrestara la usurpación y expropiación continua de tierras de las que eran víctimas ambos pueblos.

Aun cuando las comunidades indígenas ya habían iniciado la reestructuración de los resguardos coloniales y las titulaciones colectivas desde finales de los años I970, como el caso que aquí se presenta, en la década de I990 fue cuando se consolidaron la constitución y el saneamiento de la mayoría de los resguardos en el país, con el respaldo de varios artículos de la carta política: $7^{\circ}$, IO, 38, 58, 63, 286, 287, 330, y otra legislación preexistente. Además, en I99I Colombia ratificó, mediante la ley 2I de I99I, su adhesión al convenio i69 de la Organización Internacional del Trabajo (OIT), que respalda los derechos territoriales de los grupos étnicos.

En épocas diferentes indígenas y afros constituyeron organizaciones étnico-territoriales con el fin de luchar por el reconocimiento y la regulación de la propiedad de sus territorios y sus derechos como minoría étnica: consejos comunitarios en el caso de las comunidades negras, y cabildos para las indígenas. Las organizaciones deben ser entendidas como una de las dimensiones de la territorialidad, pues como anota Sack (I986) esta no puede comprenderse separada de la organización de las redes sociales ni del significado que la gente le ha dado a sus espacios. Ninguna de las dos condiciones puede sustraerse del proceso político en construcción, que busca la afirmación de esa territorialidad.

La situación legal actual de la parte baja del río Saija -resultado de una política pública que permitió el otorgamiento de derechos étnico-territoriales y de un proceso organizativo y pedagógico particular, acompañado y apoyado por distintos 
actores- quedó definida por un título colectivo de I6.II5 hectáreas para la población negra y un resguardo de 2I.32O para los indígenas (véase la tabla I).

TABLA I

RELACIÓN DE LOS TítULOS EXPEDIDOS POR EL INCODER EN EL BAJO RÍO SAIJA

\begin{tabular}{|c|c|c|c|}
\hline $\begin{array}{l}\text { TERRITORIOS ÉTNICOS DE LA } \\
\text { PARTE BAJA DEL RÍO SAIJA }\end{array}$ & $\begin{array}{c}\text { HECTÁREAS } \\
\text { DEL TÍTULO Y AÑO } \\
\text { DE ADJUDICACIÓN }\end{array}$ & ASENTAMIENTOS POBLADOS & $\begin{array}{c}\text { NÚMERO } \\
\text { DE HABITANTES } \\
\text { EN } 2004\end{array}$ \\
\hline $\begin{array}{l}\text { Resguardo Calle de Santa } \\
\text { Rosa (indígenas) }\end{array}$ & $\begin{array}{l}2 \mathrm{I} .32 \mathrm{O} . \\
1983\end{array}$ & La Sierpe y Calle Santa Rosa. & 375 \\
\hline $\begin{array}{l}\text { Consejo Comunitario de } \\
\text { la Parte Baja del río Saija } \\
\text { (negros) }\end{array}$ & $\begin{array}{l}\text { I6.II5. } \\
2002\end{array}$ & $\begin{array}{l}\text { Los Brazos, Camarones, La Troja, } \\
\text { Herradura, La Viuda, Cupí, Santa } \\
\text { Bárbara del Mar, Puerto Saija y } \\
\text { San Francisco. }\end{array}$ & 3.762 \\
\hline
\end{tabular}

\section{Titulación COLECTIVA:}

EL ADVENIMIENTO DE LA PROPIEDAD ÉTNICA Y DE LOS LÍMITES TERRITORIALES

N UN TERRITORIO BIÉTNICO POR ANTONOMASIA, CONSTITUIDO A PARTIR de prácticas espaciales conjuntas y alimentado por estrechas Ltramas sociales, la titulación concebida por límites rígidos desembocó en desencuentros. En su momento algunos académicos abogaron por una titulación que concibiera el carácter biétnico de la región, pero la propuesta careció de fuerza y el modelo actual siguió, porque la titulación indígena había sido iniciada de tiempo atrás (véanse Arocha I998; Sánchez et al., 1993) y la legislación no lograría plasmar una territorialidad móvil caracterizada por formas de uso itinerantes y flexibles. Los procesos de titulación sentaron las bases para una territorialidad demarcada por límites donde antes había fronteras fluidas, y crearon la necesidad de establecer reglas de acceso a los recursos, así como de designar titulares de los derechos de uso de los espacios, que antes se habían regido por consensos y pactos. Debe reconocerse que la delimitación territorial propuso un nuevo contorno a las relaciones interétnicas y que su ejercicio dentro de la dinámica de los cultivos para uso ilícito y del tráfico de drogas inauguró una nueva era, definida por la división del territorio.

En términos geográficos y cartográficos, la identificación de una línea es el resultado de un ejercicio que establece categorías 
por las diferencias, antes que acercarlas por las semejanzas (Retaillé, I995). Respecto a la acentuación de las primeras, la línea geográfica asumida potencia exclusiones. Pero como se mostrará, el ejercicio cartográfico no es automático y se va asumiendo a medida que las circunstancias lo imponen. Para Sack (I986) el territorio de las sociedades preindustriales está definido por acontecimientos relacionados con el lugar: la experiencia del espacio se da por procesos simbólicos que le dan sentido y por su relación con necesidades e intereses prácticos que siguen patrones tradicionales.

La concepción de un espacio independiente de eventos posibilita pensar el territorio como vacío, y ese tipo de abstracción permite, a su vez, la delimitación de fronteras claras y precisas, que surgen cuando las sociedades tienen la estructura tecnológica y geométrica para representar el espacio independientemente de los eventos. El mapa no sería más que la concepción abstracta del espacio, es decir, la representación de este que contiene los eventos, pero aparte de ellos; es una versión de la realidad plena de proposiciones porque no permite la representación de espacios vacíos ni de territorialidades fluyentes.

Esta definición ayuda a comprender el problema que surge cuando se intenta imponer el mapa como representación de las territorialidades de los grupos étnicos. Para Retaillé (I995) confinar a un grupo étnico para que permanezca inmóvil en el mapa es una simplificación alejada de la realidad, pues niega el hecho de que los grupos siempre pertenecen a conjuntos sociales más amplios y que tienen muchas más semejanzas que diferencias. La titulación territorial étnica hecha en el Pacífico es heredera de una visión exclusivista que recusó la bietnicidad de ese espacio y oficializó límites que venían siendo alimentados por el estado, la iglesia y los activistas étnicos que han acompañado los procesos de legalización territorial.

Así, deberíamos asumir que los conflictos surgen, de cierta manera, de concepciones geográficas y cartográficas de la sociedad mayor, que se agudizan cuando hay necesidad de validar los límites y controlar el acceso a los recursos. Pero esta es sólo la explicación inicial que adquiere matices de acuerdo con los procesos sociales que se han desarrollado en el área. Para entender cómo han surgido los diferentes conflictos explicaré primero cómo se dio la titulación en ambos grupos. 


\section{Titulación del resguardo de Calle de Santa Rosa}

El InCORA CONSTituyó El RESGUARDo Calle SANTA Rosa PARA lOS EPERAra-siapidara en 1983 , y en su titulación participó la iglesia católica, representada por la comunidad franciscana de la parroquia de Santa Rosa del Saija. Como en tantos otros lugares del Pacífico, la iglesia y los grupos misioneros fueron decisivos en el proceso de titulación colectiva de indígenas y negros. En el Saija llama la atención el papel que desempeñó la iglesia, aun cuando no se puede generalizar a otros contextos. Como señala Agudelo (2002), el protagonismo de la iglesia católica en los procesos sociales de la región pacífica no ha sido lineal y está lleno de contradicciones internas.

En el momento de creación del resguardo indígena la sociedad colombiana no había contemplado la titulación para las comunidades negras y ni siquiera las consideraba grupo étnico. En consecuencia, ni el Incora ni los miembros de la iglesia que acompañaron a los indígenas las consultaron. En ausencia de ellas se procedió a la titulación del resguardo en dos bloques que englobaron el asentamiento negro de Puerto Saija y varias de sus áreas de cultivo. Sin concertar los límites del título se procedió a legalizar un territorio compacto, ignorando la territorialidad ejercida por los negros en las zonas comunes de extracción y cacería. El título cobijó zonas tradicionales de trabajo de la población negra como, por ejemplo, el río Cupí, que quedó englobado dentro del resguardo indígena de Guangüí. Es de anotar que sectores indigenistas y académicos percibían y trataban a los afrocolombianos como invasores de las tierras indígenas, por lo cual fueron reducidos a colonos sin derechos territoriales y considerados por el Incora como una amenaza para los propios indígenas (Incora, I993; Arocha, I996, I998), hasta que a aquellos les llegó el turno de iniciar su propio proceso organizativo. La población negra del río Saija conoció los linderos cartográficos de los resguardos indígenas de Calle Santa Rosa, Infí y Guangüí dieciséis años después, una vez inició el trámite de su propia titulación.

La situación presentó su primera gran tensión en 1985, cuando los negros empezaron trabajos para abrir un camino que comunicaría Puerto Saija con el municipio vecino de López de Micay, camino que pasaría por el resguardo ya titulado. De acuerdo con las versiones orales y con los documentos de archivo del proceso 
de titulación, el sacerdote Jorge Gómez, quien colaboró con los trámites para la creación del resguardo, estaba en contra de la construcción de ese camino. Parece que su inmenso favor hacia los indígenas era inversamente proporcional hacia los pobladores negros. Según algunos moradores, el clérigo no sólo propagaba la segregación y la discriminación hacia los negros, sino que en una reunión instigó a los indígenas a expulsarlos del resguardo:

[...] Ya les hice el trabajo, ahora hagan respetar sus tierras. Negro que vean al interior (sic) de los resguardos deben sacarlo [...]. Ustedes van al monte, se arman y sacan los negros como dé el tiempo (Junta de Acción Costeña, 1985).

De acuerdo con la carta de protesta dirigida por la junta comunal al entonces presidente de la república, Belisario Betancur (I982-I986), el religioso, dirigiéndose a los negros, llegó a expresarse así:

[...] Ustedes qué reclaman, si estas tierras son de los indígenas. Los negros no tienen tierras aquí, ustedes son de África, sus propiedades están en África. Ustedes los negros sólo tienen concesiones, los títulos que les dio el Incora carecen de fundamento y valor, Incora los engañó.

A lo que, según la carta, un anciano respondió:

Nosotros no somos concesionarios sino colonos, Incora nos tituló tierras desde comienzos de los sesenta, cuando la reforma agraria; y además podemos mostrar títulos adjudicados del siglo pasado en I87I (Junta de Acción Costeña, I985).

El clima de convulsión no se hizo esperar y la población quedó alarmada y confundida por las informaciones que circulaban respecto a posibles expropiaciones y expulsiones. Las versiones sobre los sucesos que ocurrieron el 28 de febrero de 1985 son contradictorias: aparentemente, algunos jóvenes inconformes iniciaron un forcejeo en la casa de la comunidad religiosa, con la intención de comunicarse por radioteléfono con las autoridades en Guapi y Timbiquí. Según las memorias de una religiosa, por una mala interpretación de las palabras 
del cura los jóvenes, furiosos, entraron armados a la casa de la hermandad y encerraron en la capilla a los religiosos (Marzán, 1997).

La carta de los líderes comunitarios denuncia, por su parte, que no hubo tal y que los religiosos se hicieron pasar por secuestrados (Junta de Acción Costeña, 1985). En medio de la tensión la autoridad municipal llegó acompañada por el ejército y la policía y detuvo a los jóvenes hermanos Granja, quienes señalados como provocadores fueron absueltos una vez rindieron declaratoria. Este capítulo concluye con la salida del religioso de Puerto Saija, abucheado por la comunidad, y con la clausura de la casa de las hermanas por decisión de sus superiores en Medellín (Marzán, 1997). Luego de los acontecimientos hubo las consabidas visitas oficiales por parte de la alcaldía, la policía y el Incora: para calmar los ánimos cada institución presentó sus promesas sobre la anhelada infraestructura: caminos, escuelas, centros de salud, puesto de policía y extensión de la titulación inconclusa.

Esa disputa no desencadenó la violencia entre indígenas y negros, debido a los antecedentes de intercambios recíprocos materiales y simbólicos y a los lazos de afecto. Tanto las versiones orales como las escritas coinciden en que, aun cuando hubo momentos de mucha tensión, las relaciones no se vieron interrumpidas ni alteradas drásticamente: se comprueba que la convivencia y el diálogo se mantuvieron a pesar de las asimetrías. La carta de la Junta de Acción Costeña recoge testimonios de los indígenas, quienes:

[...] han sugerido la redacción de un memorial donde se afirme que los cholos nada tienen que ver en el asunto, pues ellos no han llamado a nadies (sic) para que los defienda y menos de los libres (negros), con los cuales nunca han tenido dificultades, entienden pues que Gómez se guía por su negrofobia. Cabe anotar que estas dos comunidades han convivido siempre armónicamente. Ha sido una relación de buena vecindad y ayuda mutua. En ellos se da una relación cuasifamiliar. Hay padrinos indígenas que lo son de niños negros y viceversa $[\ldots]$.

La misma carta continúa de este modo:

[...] Es importante anotar que en ningún momento se han presentado manifestaciones de violencia por parte de la comunidad negra. Más bien hemos sido, en extremo pasivos. Llamamos a la prefectura apostólica y a funcionarios del Incora, nosotros queremos paz, no 
queremos enfrentamientos con la comunidad indígena, a la que consideramos comunidad hermana, ni con la iglesia.

\section{Y termina:}

[...] No podemos estar tranquilos hasta tanto no sea anulada esta resolución, que prácticamente nos despoja de la tierra que por más de un siglo nos ha pertenecido, al lado, como es obvio, de las propiedades seculares de elemento indígena.

En una entrevista en mayo de 2004, Manuela Montaño, moradora de Puerto Saija, recordó que sí hubo mucho malestar, que había moradores enardecidos que querían atacar y agredir a los indígenas, pero que fueron disuadidos por quienes recordaron las relaciones de compadrazgo, amistad y colaboración entre los indígenas y los negros. "Si es que nosotros prácticamente hemos sido como hermanos, para cuanta cosa no nos hemos ayudado. Hubo personal enardecido, pero nunca pasó nada más”, comenta.

Se concluye que luego de la titulación del resguardo y del incidente con el religioso las relaciones interétnicas se reacomodaron y siguieron con sus altibajos en función de la relativa abundancia de tierras en relación con la baja densidad demográfica. La convivencia se mantuvo, pues el trabajo agrícola y maderero en las áreas tradicionales continuó; y, a decir verdad, los límites establecidos en el mapa oficial de la resolución no eran de dominio masivo ni se compadecían con la cartografía mental que tenían los miembros de ambos grupos.

De acuerdo con Sack, esto ocurre porque circunscribir las cosas en el espacio, representarlas sobre un mapa, situar lugares o identificar áreas no crea territorio. Las delimitaciones sólo se convierten en territorio cuando las fronteras son usadas para afectar los comportamientos y controlar el acceso de las personas y los recursos (1986: 14). En este caso no se estableció exclusión territorial y las prácticas de convivencia interétnica permanecieron. Por ejemplo, el lazo que Tomasa siguió manteniendo con sus compadres cholos fue una táctica más contundente y beneficiosa que separarse o aislarse. 


\section{Titulación del Consejo Comunitario DEL BAJO SAIJA}

${ }_{\text {ta }}^{\mathrm{N}}$ N RESPUESTA A LOS REQUERIMIENTOS DE LA LEY 70 DE I993 EN EL DEPARtamento del Cauca surgieron algunas organizaciones locales instancias de coordinación regional, articuladas en red con otras organizaciones existentes para apoyar el proceso de capacitación, reconocimiento y demarcación de los territorios colectivos negros a lo largo de los ríos. Lejos de ser un desarrollo lineal este se presentó con muchos altibajos y contradicciones internas. La llegada de recursos económicos considerables para ser manejados por organizaciones sin experiencia, en un contexto de precariedad económica e institucional como el de la región y sin un derrotero político definido, generó toda suerte de intríngulis para las nuevas organizaciones étnicas (Agudelo, 2002). No obstante, en el municipio de Timbiquí se demarcaron siete territorios colectivos.

En 1999, la comunidad del bajo Saija inició la organización de un consejo comunitario, requisito establecido en la ley 70 para dar paso al reconocimiento, la demarcación y la titulación territorial. De acuerdo con la legislación, el consejo comunitario es la nueva figura jurídica de autoridad en territorio colectivo. Si bien es cierto que esta estuvo precedida por otras expresiones organizativas, su importancia y, quizá, su debilidad deviene de haber nacido bajo las ordenanzas del decreto 1745 de 1995 y del andamiaje pedagógico, económico e institucional que se echó a andar para cumplir con la nueva normativa. En principio la comunidad reclamó cerca de cien mil hectáreas, pero en ese momento se conocieron las dimensiones del resguardo titulado a los indígenas de la parte alta del río y a sus vecinos más próximos. $\mathrm{Al}$ no poder transponer legalmente más de un título, el consejo comunitario del bajo Saija recibió en 2002 el título colectivo que respaldaba una propiedad de I6.II5 hectáreas.

En el proceso de titulación para comunidades negras en el Cauca hubo mucha voluntad e improvisación, se procedió con premura y faltó información y capacitación a las comunidades sobre los alcances y las propuestas de la ley 70. La mayor parte de la población negra del río Saija sigue sin comprender la normativa y subsisten dudas sobre los beneficios de esta forma de ordenamiento territorial y acerca de la institucionalidad, frente a las ventajas que tomaron procesos socioeconómicos impulsados por la siembra de coca, su procesamiento y tráfico. 
Por otra parte, la estrategia pedagógica para apoyar las reivindicaciones étnicas de los negros apenas ha comenzado, si se compara con el lugar que la población indígena ha ocupado por años en las políticas públicas de la colonia y la república. Hace veinte años la población negra era percibida como colona e invasora, como lo ejemplifica este caso. La asunción por parte de la comunidad de una identidad como grupo étnico con derechos territoriales colectivos implicó un trabajo político interno y transformaciones en la concepción y la forma de actuar de los actores locales e institucionales.

A diferencia de otras experiencias organizativas con más de veinte años en el departamento del Chocó, como la Asociación Campesina Integral del Atrato (Acia, una de las primeras organizaciones campesinas negras, anterior a la ley 70 ), en el Cauca no todos los habitantes estaban de acuerdo con tener una propiedad colectiva. Los anhelos de propiedades individuales o familiares correspondían no sólo al deseo de continuidad del proceso de titulación individual iniciado por el Incora en los años sesenta. Los habitantes de los ríos caucanos ${ }^{12}$ no percibían en ese momento la amenaza expropiadora que para el Chocó representaron la expansión ganadera paisa ${ }^{13}$ y el avance continuo de empresas madereras como Pizano S. A. (Villa, 1998), seguida por la agroindustria de palma aceitera (Mingorance, Minelli y Le $\mathrm{Du}$, 2004), que se sumaron a la maquinaria de aniquilamiento y desplazamiento implantadas por los paramilitares, las fuerzas militares del estado I2. Pese a que dichas poblaciones ya habían sufrido el impacto de las empresas de minería francesa y rusa que se asentaron en Timbiquí al comienzos y fines del siglo pasado, respectivamente (véase Tirado Mejía, 1974).

I3. Gentilicio usado para denominar a las personas del departamento de Antioquia y el viejo Caldas, aun cuando en el Pacífico se denomina así a cualquiera que provenga del interior del país. colombiano y la guerrilla contra grupos étnicos de esa parte del país por el control territorial y de los recursos. A lo largo de la década de 1990 ese modelo se expandió con distintos matices por el todo Pacífico. 


\author{
COCA Y VALOR DE CAMBIO: ¿HACIA LA \\ DISOLUCIÓN DE LA BITERRITORIALIDAD?
}

\begin{abstract}
A REGIÓN PACÍFICA COLOMBIANA SUFRIÓ EN MENOS DE UNA DÉCADA cambios dramáticos que la convirtieron en un escenario de confrontación en el que grupos armados ilegales -guerrilla y paramilitares- se disputan el control del territorio y la población. En la década de I990 el conflicto interno irrumpió definitivamente en la región y el perfil del Pacífico cambió drásticamente en materia de orden público. Para Almario (2002) y Agudelo (2002) la violencia y la coca fueron los factores que integraron el pacífico al resto del país.
\end{abstract}

La guerra entre los grupos al margen de la ley afecta de igual manera a indígenas y comunidades negras. Entre los factores que explican la agudización del conflicto en la zona la primera lectura indica una relación directa con el impactante aumento de cultivos de uso ilícito, principal fuente de financiamiento de la guerrilla y los paramilitares. Para Almario (2002) los hechos son un encadenamiento de factores que responden a una táctica premeditada de conflicto y desterritorialización en una zona que se volvió valiosa para intereses económicos y políticos. Arocha (I996) señala que las peores expresiones de violencia ocurren cuando el estado y actores económicos del desarrollo -agroindustrial y de infraestructura- dejan de darle la espalda al Pacífico para reconsiderar su posición geográfica estratégica, sus alternativas de comunicación intrarregional y sus ventajas para la inversión en proyectos de gran escala.

Por su parte, el cultivo de hoja de coca fue introducido en el Pacífico desde los años I980 por traficantes del Valle, y se incrementó rápidamente después de la fumigación aérea con glifosato

I4. La fumigación con glifosato se inició oficialmente en el andén Pacífico en Tumaco, departamento de Nariño, en diciembre de 2000. Daños ambientales como la tala de bosques y la contaminación de los ríos por la utilización de herbicidas durante el cultivo de coca -y de químicos en su procesamiento en laboratorios y cocinas- se agravan con las fumigaciones indiscriminadas promovidas y desarrolladas por el estado para su erradicación, con las consecuencias conocidas sobre los recursos y los cultivos de subsistencia. en el departamento del Putumayo, contemplada por el Plan Colombia como medida para su erradicación ${ }^{14}$. La región no había sido ajena por completo a las actividades relacionadas con la transformación de coca en cocaína y con su tráfico, ya que su posición geográfica, próxima al mar, la integró desde muy tem- 
prano a los circuitos de distribución y facilitó luego su cultivo y procesamiento. La ausencia de control estatal en el territorio y el establecimiento previo de redes para la comercialización de la hoja fueron un atractivo para la siembra in situ, que poco a poco fomentó un cambio social rápido por el arribo masivo de colonos a la región, entre otros efectos. La llegada de paisas tiene visos de permanencia, en la medida en que se detecta la afluencia de familias enteras que pueblan selvas, fundan caseríos, invaden territorios colectivos y configuran nuevas normas de restricción al acceso a determinadas áreas.

El Pacífico se convirtió en un nuevo frente de apertura agrícola, porque a pesar de las restricciones a la compra y venta en territorios étnicos ofrecía tierras baratas, situación paradójica que explicaré a continuación. Esta nueva colonización comprende una población heterogénea compuesta por personas provenientes de varios lugares del país y con distintos intereses y necesidades, entre los que se cuentan narcotraficantes de variopinto calibre, familias desplazadas por la violencia de otras regiones o en búsqueda de tierras y nuevos horizontes, campesinos afectados por las fumigaciones aéreas con glifosato en los departamentos de Caquetá, Guaviare y Putumayo, y otros tantos atraídos por el lucro que el cultivo de coca promete. Podría decirse que la característica común a esta población es su demanda de tierras, a la que acceden mediante invasiones, compraventas o negocios desventajosos.

Aun cuando numerosas transacciones para conseguirlas han sido hechas bajo presión, muchos pobladores, principalmente afrodescendientes, se sienten atraídos por la siembra de coca. Entonces, poco a poco y ante las promesas de abundancia ofrecidas por su cultivo acceden a la venta de sus tierras, mediante ventas ilegales, por medio de transacciones informales que no pueden legalizarse en la oficina de registro de instrumentos públicos. Según el artículo 63 de la Constitución los territorios colectivos están respaldados por tres íes: inalienabilidad, imprescriptibilidad e inembargabilidad ${ }^{15}$. La venta de tierras es un fenómeno complejo que supone la ignorancia de los compradores acerca de la existencia y el carácter de los territorios étnicos, y el desconocimiento por parte de los vendedores de los derechos y las obligaciones

I5. El artículo 63 de la Constitución política dice: "Los bienes de uso público, los parques naturales, las tierras comunales de grupos étnicos, las tierras de resguardo, el patrimonio arqueológico de la nación y los demás bienes que determine la ley, son inalienables, imprescriptibles e inembargables". 
legales relativas a los territorios. Son compradores de mala fe los terceros que adquieren tierras y hacen una ocupación indebida de las propiedades étnicas.

Las ventas presentan estas modalidades:

- Venta directa a terceros que llegan a la región y compran tierra directamente a las familias. En algunas zonas como Timbiquí se incurre en ventas de parcelas pertenecientes a otras familias e incluso a familias de otro grupo.

- Compra por parte de miembros de la misma etnia, cuando los foráneos tienen conocimiento de la figura de territorios colectivos y de sus implicaciones legales.

- Compra a propietarios individuales que consiguieron su título antes de los procesos de titulación colectiva. Estas personas venden sus tierras a foráneos que, muchas veces, toman más de la comprada e invaden terrenos colindantes. Algunas de estas ventas suelen ser hechas desde Buenaventura y Cali, donde viven los propietarios de títulos individuales que tampoco están familiarizados con las disposiciones de la ley 70 de 1993.

- Arrendamiento mediante el cual se alquilan zanjas, lotes, parcelas y bosques.

La siembra de hoja de coca ha provocado una demanda mercantil de tierras sin precedentes en el Pacífico, que desata toda suerte de conflictos intergeneracionales en las familias y la comunidad, e interétnicos cuando se venden las parcelas de una familia que están englobados dentro de los límites de la otra etnia. El valor de uso de la tierra está cambiando radicalmente por un valor de cambio, que altera los sistemas tradicionales de producción y el modo de acceso y apropiación, situación que ha transformado aceleradamente los referentes socioespaciales.

En el caso de las comunidades negras, el artículo 33 del decreto I745 de 1995 posibilita la enajenación o la venta del usufructo de las áreas correspondientes a un grupo familiar por parte del titular o titulares de este derecho. Para ello se necesita contar con la aprobación de la junta del consejo comunitario. Sin embargo, en el caso del municipio de Timbiquí las juntas no son una autoridad reconocida y acatada plenamente, y, por tanto, dicho control escapa de sus posibilidades reales. El mismo artículo dice que 
el ejercicio del derecho preferencial de adquisición de usufructo únicamente podrá recaer en otro miembro de la comunidad respectiva o en su defecto en otro miembro del grupo étnico. Al indagar entre los pobladores negros del Saija las razones por las cuales vendían encontré varias respuestas: desde la oposición vehemente de los habitantes más viejos a la venta de tierra en las que han incurrido algunos hasta afirmaciones como: "Estos son bosques nacionales, que no tienen dueño", o "Todo esto son terrenos baldíos del estado". Estas respuestas muestran que en las comunidades se vive una tensión al respecto, que ha cobrado víctimas en razón de los desencuentros.

De lo anterior no se debe concluir que esta sea una situación generalizable a todo el Pacífico ni mucho menos inferir que la titulación colectiva para comunidades negras ha sido un fracaso. Pero no se puede negar la existencia de un efecto inesperado, resultado de una sumatoria de factores internos y externos: por un lado, se detectan fallas en la estrategia pedagógica desarrollada por las organizaciones étnico-territoriales para capacitar a las comunidades en cuanto a sus derechos y deberes respecto al territorio. Aprender el contenido de las leyes y las obligaciones administrativas requiere tiempo y recursos, y en Timbiquí las juntas directivas de los consejos comunitarios no poseen las capacidades administrativas ni los instrumentos de control para sancionar las ventas, ni los recursos para la gestión y el ordenamiento. Además, ningún consejo comunitario cuenta con sede de trabajo, medios de transporte o de comunicación. Esos factores reunidos constituyen uno de los obstáculos para la construcción del autogobierno y contribuyen al debilitamiento de la organización.

Por otro lado, la venta de las posesiones pone en evidencia problemas económicos estructurales, tal como lo señalaron algunos indígenas, que también han sido cautivados por los beneficios inmediatos que ofrece el cultivo de coca -bienes y servicios-. Muchos pobladores locales ven en el auge coquero una auténtica oportunidad económica. Aunque los capítulos $\mathrm{V}$ y VII de la ley 70, por ejemplo, contemplan el impulso de planes de desarrollo económico para las comunidades negras, no han sido reglamentados y son letra muerta. Además, el Banco Agrario, única entidad que acepta la condición del artículo 63 de la Constitución para otorgar préstamos, se niega a hacerlo por falta de una política que viabilice los recursos. 
La venta de tierras ha llevado también al surgimiento de serios conflictos interétnicos agudizados por la presencia de capitales foráneos, armas y cultivos de uso ilícito. Aun cuando entre miembros de las dos etnias no se han registrado hechos de violencia o muerte por este motivo, sí se comprueba el endurecimiento de la frontera étnica. En más de una oportunidad las autoridades indígenas han activado el límite cartográfico, impidiendo el acceso de los negros a zonas donde otrora no existía veda alguna. En consecuencia, muchas familias negras deben gestionar permisos con las autoridades del resguardo para acceder a ríos y a sus propias parcelas, como es el caso del río Cupí y el área de la quebrada Cocorota, donde además se quejan de haber encontrado algunas chozas de paso quemadas y fetiches de brujería elaborados por los indígenas.

La restricción a las tierras es producto también de la vinculación de los indígenas con los colonos, quienes muchas veces imponen nuevas reglas de uso, condicionando su aparcería a la prohibición de extraños. Las acusaciones mutuas no se hacen esperar: mientras los indígenas reivindican el uso correcto y ecológico que hacen de su territorio y culpan a los negros de la expansión del cultivo de coca, los afrodescendientes dicen que los indígenas tienen tierras de más. Ese tipo de medidas afecta en general a todos los negros y no sólo a quienes se hallan vinculados con las actividades ilícitas. Ese proceder excluyente nos recuerda que el territorio se crea (Sack, 1986). En este caso se observa el proceso de creación de un territorio uniétnico donde se modela el comportamiento de las personas dentro de unos límites y se impide a otros tener acceso a los recursos y al espacio.

Como proceso situacional de adscripción política la etnicidad pasa por periodos durante los que la diferenciación no es importante y por otros, como en este caso, cuando las relaciones interétnicas activan los dispositivos de inclusión y exclusión que reivindican con marcado acento las diferencias entre nosotros y ellos. Al revisar el marco legal étnico-territorial vigente se comprueba la dificultad de plasmar en la legislación una territorialidad que tenía formas itinerantes y flexibles, y la frontera étnica se robustece en la medida en que los comportamientos de un grupo aparecen como amenaza para el otro. Este caso ejemplifica cómo formas de fronteras distinguibles se vuelven importantes cuando los grupos étnicos se hallan bajo presión (Eriksen, 1993). Aquí, el sincretismo y el intercambio fluido de bienes y servicios 
que habían servido como una solución cultural al conflicto social y a la tensión por la superposición territorial parece un mecanismo desgastado. Eriksen plantea que la etnicidad, que surge en circunstancias de agitación y transformación social, se caracteriza también por erosiones culturales severas y por la desaparición de las costumbres que servían como marcas de diferenciación. En el contexto de Timbiquí nos enfrentamos al reto de entender entonces cómo es que esa identidad se mantiene, ya que como anota Epstein (I978, citado por Eriksen, I993) para las sociedades que se encuentran en procesos rápidos de cambio social y cultural, la etnicidad no desaparece y, contra las expectativas, emerge en formas nuevas, más estrictas, como hemos visto.

\section{PARA NO CONCluir}

L RECONOCIMIENTO JURIDICO DE LAS REIVINDICACIONES TERRITORIALES DE - los grupos étnicos buscaba crear un nuevo ordenamiento terri-torial; sin embargo, el escenario que protegería sus tierras en el Pacífico colombiano se vio interrumpido por las dinámicas de la siembra de cultivos de uso ilícito y el tráfico de drogas. La fuerza de esa dinámica impuso de manera más efectiva el esquema de ordenamiento territorial actual, que además de seguir excluyendo a los pobladores ancestrales a favor de terceros propicia la separación entre las etnias asentadas en la región.

$\mathrm{Al}$ abordar las consecuencias de ese proceso violento se reflexionó sobre cómo se refleja en el ordenamiento, el control y el manejo del espacio. La territorialidad, caracterizada por el manejo conjunto de dos grupos humanos, terminó por asumir las formas rígidas de delimitación propuestas por las titulaciones, no como efecto del proceso de legalización territorial, sino por la articulación del Pacífico caucano a las dinámicas del cultivo de coca, el tráfico de cocaína y la guerra.

Por ahora nos queda la duda, ¿creará el gobierno mecanismos de protección territorial para los grupos étnicos? O ise convertirán la venta de las posesiones y la siembra de coca en los territorios colectivos de negros e indígenas en terreno abonado para que el gobierno active expropiaciones y acelere la puesta en marcha de planes de ordenamiento territorial que incluyen inversiones considerables de capital, como la palma aceitera? 
El gobierno colombiano no ha actuado legalmente al respecto, no porque desconozca la situación, sino por que frente a esta problemática no ha desarrollado los procedimientos requeridos. Las ventas ilegales no están siendo castigadas, porque la política gubernamental está concentrada en atacar las drogas ilícitas por sus causas más visibles -el cultivo mismo- mediante fumigaciones aéreas con glifosato, en capturar a grandes capos y en la interceptación de las redes de comercio. Efectos colaterales de la siembra de coca, como el desvanecimiento del carácter biétnico del territorio y el surgimiento de enfrentamientos que están tomando carácter étnico y territorial por la escasez de tierras cultivables no son considerados y no hacen parte de ninguna agenda gubernamental.

\section{Bibliografía}

Agudelo, Carlos Efrén. 2004. Politique et populations noires en Colombie. Enjeux du multiculturalisme. L’Harmattan Recherches Amériques Latines. París.

2002. "Poblaciones negras y política en el Pacífico colombiano: paradojas de una inclusión ambigua" Tesis para obtener el grado de doctor en sociología. Universidad París III.

Almario, Óscar. 2002. "Dinámica y consecuencias del conflicto armado colombiano en el Pacífico: limpieza étnica y desterritorialización de afrocolombianos e indígenas y "multiculturalismo" de Estado e indolencia nacional". Ponencia presentada en el seminario internacional "Dimensiones territoriales de la guerra y la paz en Colombia". Simposio 8, Procesos de guerra y paz en el litoral Pacífico. Universidad Nacional de Colombia y Red de Estudios de Espacio y Territorio. Bogotá io al I3 de septiembre.

. 1996. "Territorio, poblamiento y sociedades negras en el Pacífico sur colombiano". En Jorge Ignacio del Valle y Eduardo Restrepo (eds.). Renacientes del guandal. Grupos negros en los ríos Satinga y Sanquianga. Universidad Nacional de Colombia-Proyecto Biopacífico. Bogotá.

Aprile-Gniset, JACQUes. 1993. Poblamiento, hábitats y pueblos del Pacífico. Universidad del Valle. Cali.

Arocha, Jaime. 1999. Ombligados de Ananse. Hilos ancestrales y modernos en el Pacífico colombiano. Universidad Nacional de Colombia, facultad de ciencias humanas-CES. Bogotá. 
AROCHA, JAIME. I998. "La inclusión de los afrocolombianos ¿Meta inalcanzable? En Geografía humana de Colombia. Tomo IV Los afrocolombianos. Instituto Colombiano de Cultura Hispánica. Bogotá.

- 1996. "Afrogénesis, eurogénesis y convivencia interétnica". En Arturo Escobar y Álvaro Pedrosa (eds.). Pacífico ¿Desarrollo o diversidad? Estado, capital y movimientos sociales en el Pacífico Colombiano. Cerec-Ecofondo. Bogotá.

Barth, Frederick. I969. Ethnic groups and boundaries. The social organization of the difference. Scandinavian University Press. Oslo.

Consejo Comunitario Parte Baja del Río Saija. 2000. "Acta de reunión interétnica $\mathrm{n}^{\mathrm{O}} \mathrm{I}$ ".

ERIKSen, Thomas Hylland. 1993. Ethnicity and nationalism. Anthropological perspectives. Pluto Press. Londres.

INCORA. 2002. "Resolución número 002245 de adjudicación de tierras de las comunidades negras”. Incora. Bogotá.

- I993. "Informe socioeconómico y de tenencia de tierras de las comunidades eperara-siapidara de Guangüí e Infí asentadas en la cuenca del río Saija, municipio de Timbiquí, departamento del Cauca”. Subgerencia de adquisición y dotación de tierras, división de resguardos indígenas. Bogotá.

I982. "Resolución 4II52". Incora. Bogotá.

Junta de Acción Costeña. I985 "Carta dirigida al señor presidente de la república Belisario Betancourt Cuartas”.

Losonczy, AnNe Marie. 1997. "Hacia una antropología de lo inter-étnico: una perspectiva negro-americana e indígena”. En María Victoria Uribe y Eduardo Restrepo (eds.). Antropología en la modernidad. Instituto Colombiano de Antropología. Bogotá.

Marzán, Consuelo de Jesús (hermana). I997. "Puerto Saija: una experiencia de la relación de dios con su pueblo. Una aproximación desde su historia”. Trabajo de investigación para obtener la licenciatura en ciencias sociales con énfasis en antropología. Universidad Pontificia Bolivariana. Medellín.

Mingorance, Fidel, Flaminia Minelli y Hélene Le Du. 2004. El cultivo de la palma africana en el Chocó. Legalidad ambiental, territorial y derechos humanos. Editorial Codice-Human Rights EverywhereDiócesis de Quibdó. Bogotá.

Nietschmann, Bernard. I987. "The Third World war”. Cultural Survival Quaterly. II (3).

OfFEn, KARL. 2003. "The territorial turn: Making black territories in Pacific Colombia”. Journal of Latin American Geography. 2. 
Restrepo, Eduardo y Claudia Leal. 2003. Unos bosques sembrados de aserríos. Historia de la extracción maderera en el Pacífico colombiano. Universidad de Antioquia. Medellín.

Retaillé, Denis. I995. "Etnogeographie: naturalization des formes socio-spatiales”. En Paul Claval y Singaravelou. Etnogeographie. L’Harmattan. París.

Romero, Mario Diego. I99I. "Sociedades negras: esclavos y libres en la costa Pacífica colombiana”. América Negra. 2.

SACK, ROBERT. 1986. Human territoriality. Its theory and history. Cambrigde University Press. Cambridge.

SÁnchez, EnRique, Roque Roldán y María Fernanda Sánchez. I993. Derechos e identidad: los pueblos indígenas y negros en la Constitución política de Colombia 1991. Coama-Unión Europea-Disloque Editores. Bogotá.

SÁnchez, EnRique, Raúl Arango et al. 2002. Los pueblos indígenas de Colombia en el umbral del nuevo milenio. Población, cultura y territorio: bases para el fortalecimiento social y económico de las comunidades indígenas. Departamento Nacional de Planeación, dirección de desarrollo territorial. Bogotá.

Tirado Mejía, Álvaro. 1974. "El caso de las minas de Timbiquí”. Cuadernos Colombianos. I.

VILA, W ILAAM. 1998. "Movimiento social de comunidades negras en el Pacífico colombiano. La construcción de una noción de territorio y región”. En Geografía humana de Colombia. Tomo IV. Los afrocolombianos. Instituto Colombiano de Cultura Hispánica. Bogotá. 